\title{
Hesitancy towards COVID-19 Vaccination among Healthcare Workers: A Multi-Centric Survey in France
}

\author{
Cécile Janssen ${ }^{1}$, Alexis Maillard ${ }^{2}$, Céline Bodelet ${ }^{3}{ }^{\circledR}$, Anne-Laure Claudel ${ }^{2}$, Jacques Gaillat ${ }^{2}$, Tristan Delory ${ }^{2, *}$ \\ and on behalf of the ACV Alpin Study Group ${ }^{+}$ \\ 1 Centre Hospitalier Annecy Genevois, Infectious Diseases Unit, F-74374 Annecy, France; \\ cjanssen@ch-annecygenevois.fr \\ 2 Centre Hospitalier Annecy Genevois, Clinical Research Unit, F-74374 Annecy, France; \\ maillard.alexis@laposte.net (A.M.); alclaudel@ch-annecygenevois.fr (A.-L.C.); \\ jgaillat@ch-annecygenevois.fr (J.G.) \\ 3 Laboratoire Inter-universitaire de Psychologie (LIP-PC2S), Université Grenoble, Alpes 1251 Avenue Centrale, \\ 38400 Saint-Martin-d'Hères, France; celine.bodelet@univ-grenoble-alpes.fr \\ * Correspondence: tdelory@ch-annecygenevois.fr \\ † The ACV Alpin Study Group are listed in acknowledgments.
}

Citation: Janssen, C.; Maillard, A.; Bodelet, C.; Claudel, A.-L.; Gaillat, J.; Delory, T.; on behalf of the ACV Alpin Study Group Hesitancy towards COVID-19 Vaccination among Healthcare Workers: A Multi-Centric Survey in France. Vaccines 2021, 9, 547. https://doi.org/10.3390/ vaccines 9060547

\section{Academic Editors:}

Luis Martinez-Sobrido and Barbara Rath

\section{Received: 24 April 2021}

Accepted: 19 May 2021

Published: 22 May 2021

Publisher's Note: MDPI stays neutral with regard to jurisdictional claims in published maps and institutional affiliations.

Copyright: (c) 2021 by the authors. Licensee MDPI, Basel, Switzerland. This article is an open access article distributed under the terms and conditions of the Creative Commons Attribution (CC BY) license (https:// creativecommons.org/licenses/by/ $4.0 /)$.

\begin{abstract}
Vaccination programs against COVID-19 are being scaled up. We aimed to assess the effects of vaccine characteristics on vaccine hesitancy among healthcare workers in a multi-center survey conducted within French healthcare facilities from 1 December 2020 to 26 March 2021. We invited any healthcare workers naïve of COVID-19 vaccination to complete an online self-questionnaire. They reported on their socio-demographic characteristics, as well as their perception and beliefs towards vaccination. We measured their willingness to get vaccinated in eight scenarios for candidates' vaccines presented sequentially ( 1 to 4 -point scale). Candidates' vaccines varied for efficacy ( $25 \%$, $50 \%, 100 \%)$, length of immunization (1 year or lifetime), frequency $(<1 / 100,<1 / 10,000)$, and severity (none, moderate, severe) of adverse events. We analyzed 4349 healthcare workers' responses with interpretable questionnaires. The crude willingness to get vaccinated was $53.2 \%$ and increased over time. We clustered the trajectories of responses using an unsupervised classification algorithm (k-means) and identified four groups of healthcare workers: those willing to get vaccinated in any scenario $(18 \%)$, those not willing to get vaccinated at all $(22 \%)$, and those hesitating but more likely to accept $(32 \%)$ or reject $(28 \%)$ the vaccination depending on the scenario. In these last two subgroups, vaccine acceptance was growing with age, educational background and was higher among men with condition. Compared to an ideal vaccine candidate, a 50\% reduced efficacy resulted in an average drop in acceptance by 0.8 ( $\mathrm{SD} \pm 0.8,-23.5 \%)$, while it was ranging from $1.4(\mathrm{SD} \pm 1.0,-38.4 \%)$ to 2.1 ( $\mathrm{SD} \pm 1.0,-58.4 \%)$ in case of severe but rare adverse event. The acceptance of a mandatory immunization program was $29.6 \%$ overall and was positively correlated to the willingness to get vaccinated, ranging from $2.4 \%$ to $60.0 \%$. Even if healthcare workers represent a heterogeneous population, most $(80 \%)$ could accept the vaccination against COVID-19. Their willingness to get the vaccine increased over time and as immunization programs became available. Among hesitant professionals, the fear of adverse events was the main concern. Targeted information campaigns reassuring about adverse events may increase vaccine coverage, in a population with a strong opinion about mandatory immunization programs.
\end{abstract}

Keywords: COVID-19; vaccination; hesitancy; healthcare workers; cross-sectional survey; clustering; unsupervised learning

\section{Introduction}

The massive scaling-up of immunization programs is essential to tackle the COVID-19 pandemic and progressively reduce the burden of bundles of preventive measures [1]. 
On the frontline, healthcare workers have a high risk of infection and are a key population for vaccination, as their protection serves the preservation of the healthcare system [2-5]. A high coverage among these professionals could also increase vaccination acceptance within the general population.

However, during the last 2009 A(H1N1) influenza pandemic, the global vaccine coverage remained below 50\% among healthcare workers [6,7]. In Europe, the coverage for seasonal influenza vaccines ranges from $27.5 \%$ in Spain to $54.7 \%$ in UK-Wales (2018) [8]. It is also known that healthcare workers are a heterogeneous population in their attitudes towards vaccination in general [9]. In France, the 2018-2019 coverage for flu among caregivers working in a hospital was $34.8 \%$ and varied by area, occupation, age, and sex [10].

To decipher COVID-19 vaccine hesitancy and highlights its determinants, we conducted a multi-centric survey evaluating vaccine acceptance for different vaccine candidates among healthcare workers of French institutions.

\section{Materials and Methods}

\subsection{Study Context, Design, and Population}

We conducted a multi-centric cross-sectional survey among healthcare workers of French institutions, including public hospitals, private hospitals, and nursing homes. Twenty-one chief executive officers of French healthcare facilities agreed to participate in the study. Any participating institution had to broadcast to their staff members a QR-code and a web-link, by e-mail, notice on the intranet of institutions, hanging of advertising posters within the institution, or adding an advertising notice to the monthly pay slip. These links were redirecting to an online self-questionnaire (supplementary materials). Data were collected from 1 December 2020 to 26 March 2021. On 16 March 2021, we contacted the participating sites to broadcast a reminder to their staff members.

The national immunization campaign for French healthcare workers started on 4 January, with the scaling-up of the BNT162b2 mRNA vaccine (Pfizer-BioNTech). Initially, any healthcare worker aged 50 and older was eligible for vaccination. From 6 February to 15 March 2021, those aged 50 and below were eligible for the AZD1222 adenovirus vaccine (AstraZeneca). From the 15 March to the 19 March, following an European Medicines Agency warning, French health authorities temporarily banned the AZD1222 adenovirus vaccine for safety reasons [11]. It was then re-authorized for staff aged 55 and above only. At the same date, all healthcare workers became eligible for the BNT162b2 mRNA vaccine.

\subsection{Self-Questionnaire}

A unique quick response (QR)-code and web link to reach the self-questionnaire were provided to each institution. Data collected through the online self-questionnaire were anonymous. After flashing the QR-code or clicking the web link, employees had to report their vaccine status towards COVID-19.

\subsection{Scenario of Candidate Vaccines}

Each scenario was characterized by different vaccine efficacy $(25 \%, 50 \%, 100 \%)$, length of immunization (1 year, lifetime), frequency $(<1 / 100,<1 / 10,000)$, and severity of the induced adverse event (none, moderate, severe). In any scenario, we hypothesized that COVID-19 epidemic would become annual and seasonal. Scenarios were sequentially ordered from first to last. The first scenario was an ideal vaccine candidate with $100 \%$ efficacy, lifetime immunization, and no induced adverse events. Scenarios are detailed in Supplementary Table S1.

\subsection{Outcomes/Statistical Analysis}

We first estimated the crude willingness to get vaccinated against COVID-19 vaccination and over time (in weeks). Then we estimated the evolution of the willingness towards COVID-19 vaccine through scenario analysis, starting from an ideal vaccine candidate 
(first scenario). We considered the sequential measurement of willingness as a longitudinal array, corresponding for each respondent, to a trajectory of vaccine acceptance. For complete cases, we clustered individual trajectories to identify subgroups of attitudes towards vaccine acceptance using the measurement of temporal Euclidean distance ( $\mathrm{k}$-means for longitudinal data) [12]. Based on the Elbow method, we determined that four clusters would explain $\sim 80 \%$ of the variance: (1) those willing to be vaccinated at any cost; (2) those hesitating but likely to get vaccinated; (3) those hesitating but not likely to get vaccinated; and (4) those not willing to get vaccinated at all. We used frequencies (percentages), and median (interquartile range) to describe these four clusters. Among hesitant healthcare workers, we estimated the conditions which negatively impacted vaccine acceptance: efficacy $(100 \%$ to $50 \%$ ), adverse event severity (none to moderate, to severe), or length of immunization (lifetime to 1 year). We finally compared potential leverages to increase willingness to get vaccinated by comparing healthcare workers' beliefs about COVID-19 vaccination. We used the chi-squared test and the Fischer exact test to compare frequencies between clusters. We also used the Student t-test and the Mann-Whitney test to compare distributions. We set the level of significance to $5 \%$ bilateral $(p$-value $<0.050)$. All analyses were performed on the R software version 4.0.3 (The R Project for Statistical Computing, Vienna, Austria). We used the 'kml' and 'ggplot2' packages.

\section{Results}

Over the study period, more than 45,000 workers from 21 healthcare facilities were reached, of whom 8773 opened the online survey: 711 were vaccinated and were therefore excluded from clustering analyses, 4349 had exploitable responses, and were thereby included in the analyses (Figure 1). The sample was mainly composed of women (74.4\%), aged 25 to $50(71.3 \%)$, with a broad range of educational levels, and a third having a master's degree or higher. Half of the participants were acting as frontline caregivers, including $31.8 \%$ nurses and nurse assistants and $14.4 \%$ physicians. The majority $(86.7 \%)$ were working in public hospitals, and the remaining in private facilities or nursing homes.

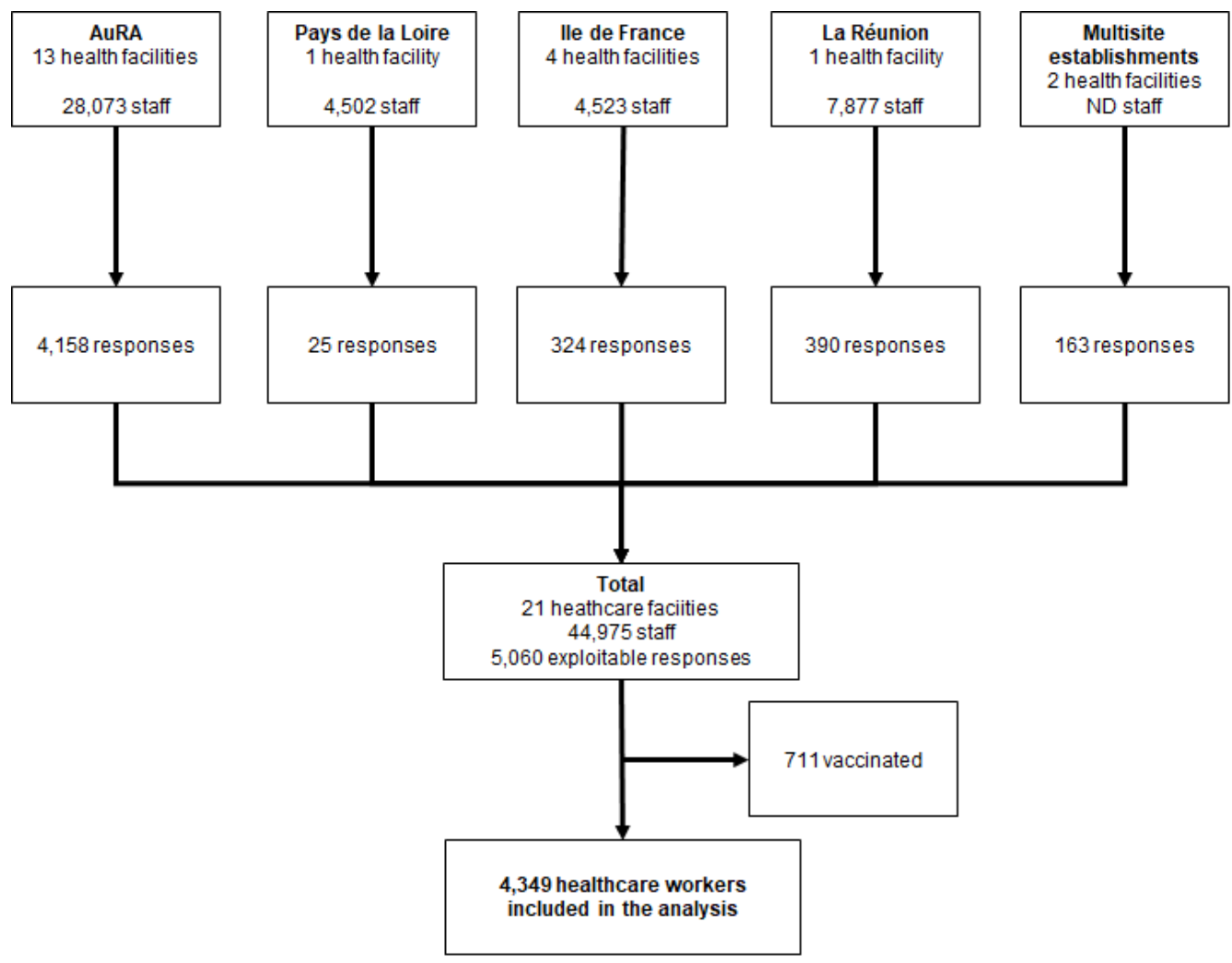

Figure 1. Study flow chart. ND—not-defined. 
The crude willingness to get vaccinated against COVID-19 (including already vaccinated respondents) was $53.2 \%$ overall (4,558 responses), including $15.6 \%$ vaccinated, $21.8 \%$ definitely, yes, and $16.8 \%$ yes, likely. Others were neutral $(11.9 \%)$, not likely $(19.8 \%)$, or not willing to get vaccinated at all (14.1\%). After the start of the immunization program, the proportion of respondents of the poll vaccinated against COVID-19 reached 59.1\% after 10 March 2021. As illustrated in Figure 2, the willingness increased over the study period $\left(r^{2}=0.010, p\right.$-value $\left.<0.001\right)$.

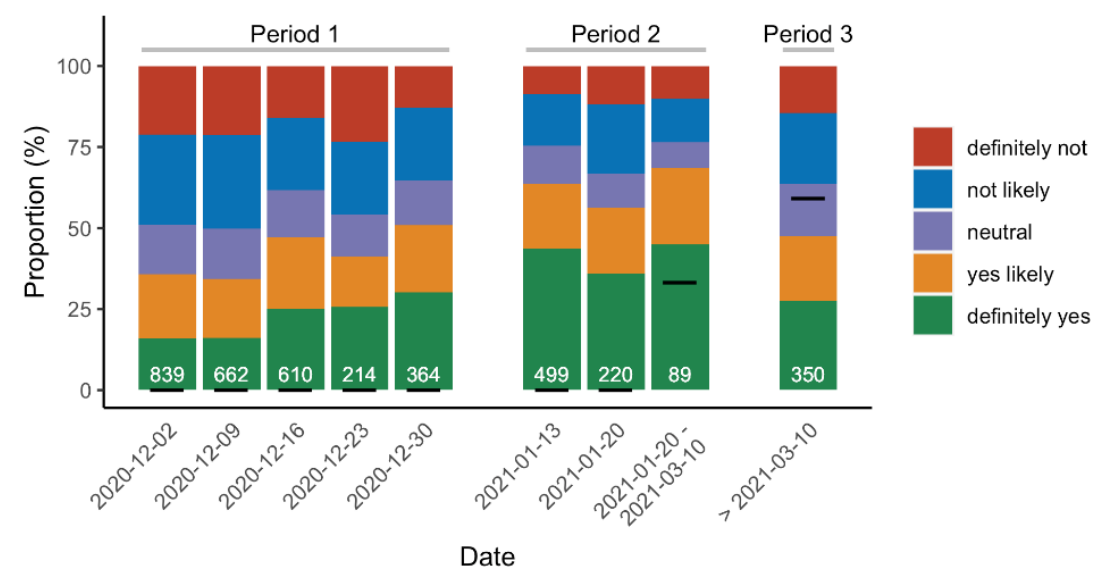

Figure 2. Time course of raw-willingness score to be vaccinated against COVID-19. White numbers represent the number of participants enrolled each week (poll time points). Participants were categorized in 5 groups according to their self-reported crude willingness to be vaccinated against COVID-19 (1 to 7 scale): definitely, yes (7), yes, likely (5-6), neutral (4), not likely (2-3), definitely, not (1). Black bars show the proportion of vaccinated respondents. Period 1: no vaccine available. Period 2: BNT162b2 mRNA vaccine available for healthcare workers $>50$ years and AZD1222 adenovirus vaccine for those $<50$ years. Period 3: BNT162b2 mRNA vaccine for any healthcare worker, and AZD1222 adenovirus vaccine for those $>55$ years only (after a temporary ban for safety concerns).

\subsection{Scenario and Vaccine Acceptance}

We presented eight candidate vaccine scenarios to participants, always in the same order, varying for efficacy, duration of immunity, and adverse events. Complete responses for candidate vaccines were available for $3732(85.8 \%)$ of respondents, which were clustered. Figure 3A shows the evolution (trajectories) of vaccine acceptance over the scenario (scale of 1 to 4, from 1, "Definitely, not" to 4, "Definitely, yes"). The average acceptance decreased from a maximum of $3.4(\mathrm{SD} \pm 0.9$ ) with an ideal vaccine candidate (scenario 1$)$ to a minimum of $1.7(\mathrm{SD} \pm 0.9)$ in the worst-case scenario (scenario 7), with the lowest efficacy and the worst side effects.

The k-means algorithm clustered participants into four subgroups for vaccine acceptance (Figure 3B): those with almost constant negative answers (group "Never"), those with almost constant positive answers (group "Always"), and the two remaining hesitant groups despite a trend to rather positive ("Hesitant but willing" group) or negative ("Hesitant but not willing" group) willingness. 

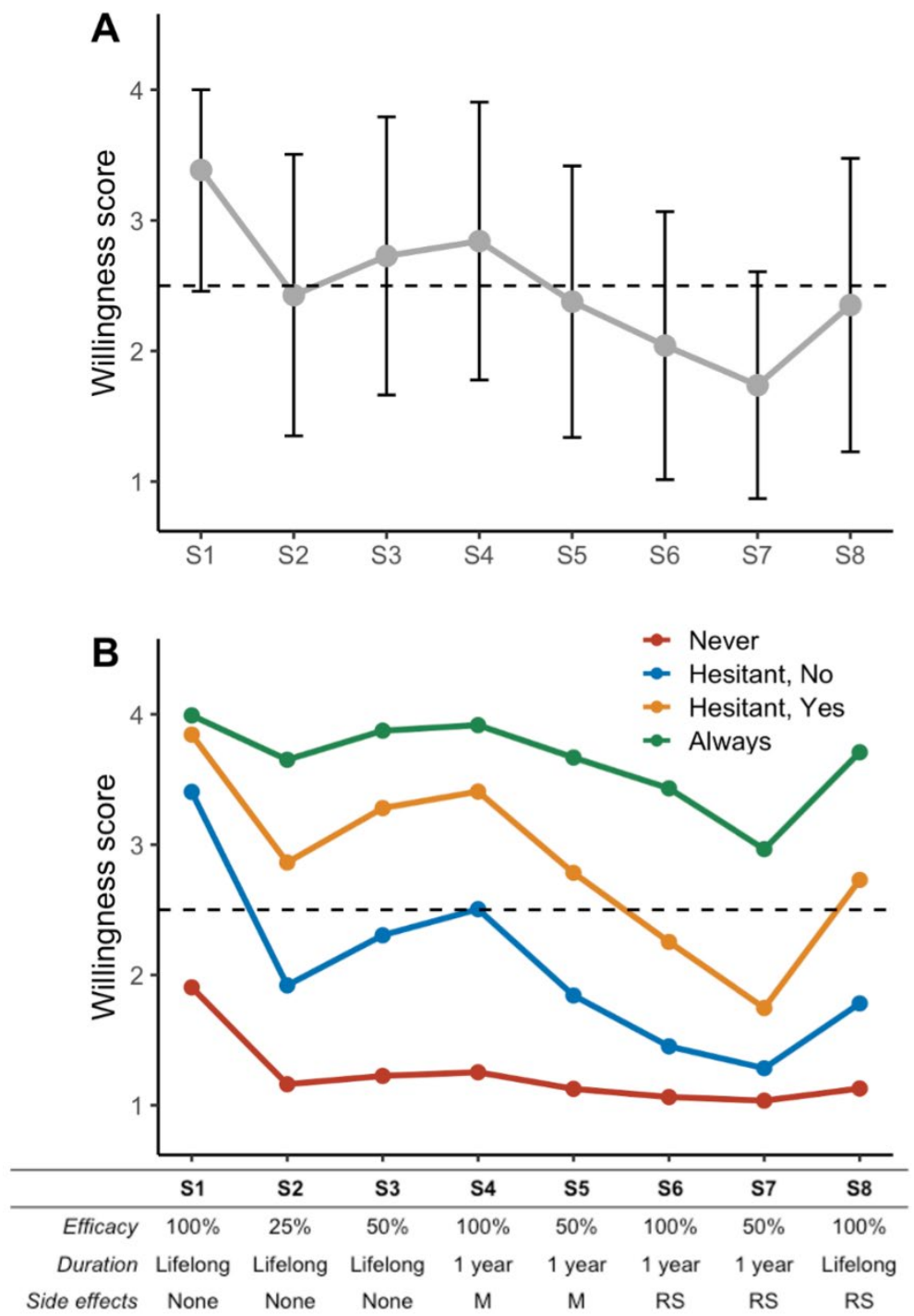

Figure 3. Trajectory of responses to vaccine scenarios and clustering. Eight vaccine candidate scenarios were submitted to participant in the same order from \#1 (S1, ideal vaccine candidate conferring a lifelong immunity with 100\% efficacy and no adverse events) to \#8 (S8). Vaccine efficacy ranges from $25 \%$ to $100 \%$. Immunization duration was 1-year to lifelong. Side effects were absent, moderate (M) or rare but severe (RS). Participant scored (1 to 4 scale) each scenario according to their willingness to be vaccinated with the proposed candidate from 1 ("Not at all") to 4 ("Definitely"). (A) Average trajectory of responses across the scenarios; error bars represent standard-deviations, dashed horizontal line the limit between scores in favor (above) or in disfavor (below) of vaccine acceptance. (B) Average trajectories of vaccine acceptance for the four clusters obtained using a k-mean algorithm for longitudinal data (see methods): "Never" group in red, "Always" group in green, "Hesitating but willing" group in yellow and "Hesitating and not willing" group in blue.

\subsection{Cluster Characteristics}

The characteristics of each clusters' staff members are described in Table 1. Workers not likely or not willing at all to get the vaccine were the youngest, more frequently women, less educated, and working in administrative functions with a relatively lower income. They also had a low coverage for mandatory vaccines-hepatitis B, combined (diphtheria, tetanus, poliomyelitis), and whooping cough-and yearly recommended influenza vaccination (17.6\% to $42.3 \%$ versus $75.3 \%$ to $91.1 \%$ in others, $p<0.001$ ). Exposure to COVID-19 cases and rate of infection was similar across clusters, though the frequency of risk factors for severe COVID-19 infection was higher in those willing to get the vaccine. 
Table 1. Characteristics of respondents by cluster.

\begin{tabular}{|c|c|c|c|c|c|c|c|}
\hline \multirow{2}{*}{ Characteristics } & Missing & Never & $\begin{array}{c}\text { Hesitating } \\
\text { But Not Willing }\end{array}$ & $\begin{array}{l}\text { Hesitating } \\
\text { But Willing }\end{array}$ & Always & Overall & \multirow[t]{2}{*}{$p$-Value } \\
\hline & $\%$ & $N=675$ & $\mathrm{~N}=1190$ & $\mathrm{~N}=1050$ & $\mathrm{~N}=817$ & $N=4349$ & \\
\hline Age group & 16.7 & & & & & & $<0.001$ \\
\hline$<25$ years & & $52(8.0 \%)$ & $69(6.0 \%)$ & $49(4.8 \%)$ & $32(4.0 \%)$ & $202(5.6 \%)$ & \\
\hline $25-40$ years & & $338(52.3 \%)$ & $522(45.4 \%)$ & $473(46.1 \%)$ & $342(42.6 \%)$ & $1675(46.2 \%)$ & \\
\hline $41-50$ years & & $131(20.3 \%)$ & $317(27.6 \%)$ & $250(24.4 \%)$ & $210(26.2 \%)$ & $908(25.1 \%)$ & \\
\hline$>50$ years & & $125(19.3 \%)$ & $241(21.0 \%)$ & $254(24.8 \%)$ & $218(27.2 \%)$ & $838(23.1 \%)$ & \\
\hline Sex, female & 16.7 & $531(82.2 \%)$ & $951(82.8 \%)$ & $800(78.0 \%)$ & $524(65.3 \%)$ & $2806(77.4 \%)$ & $<0.001$ \\
\hline Educational level & 27.4 & & & & & & $<0.001$ \\
\hline High school diploma or less & & $67(13.6 \%)$ & $89(9.2 \%)$ & $37(4.0 \%)$ & $16(2.1 \%)$ & $209(6.6 \%)$ & \\
\hline Bachelor's degree & & $284(57.6 \%)$ & $544(56.3 \%)$ & $407(43.6 \%)$ & $237(31.0 \%)$ & $1472(46.6 \%)$ & \\
\hline Master or higher & & $71(14.4 \%)$ & $216(22.3 \%)$ & $391(41.9 \%)$ & $431(56.3 \%)$ & $1109(35.1 \%)$ & \\
\hline Other & & $71(14.4 \%)$ & $118(12.2 \%)$ & $99(10.6 \%)$ & $81(10.6 \%)$ & $369(11.7 \%)$ & \\
\hline Professional category + & 16.8 & & & & & & $<0.001$ \\
\hline Frontline caregiver & & $289(44.9 \%)$ & $551(48.0 \%)$ & $573(55.8 \%)$ & $527(65.8 \%)$ & $1940(53.6 \%)$ & \\
\hline Other caregiver & & $180(28.0 \%)$ & $357(31.1 \%)$ & $301(29.3 \%)$ & $180(22.5 \%)$ & $1018(28.1 \%)$ & \\
\hline $\begin{array}{l}\text { Administrative and non- } \\
\text { caregiver staff }\end{array}$ & & $165(25.7 \%)$ & $228(19.9 \%)$ & $145(14.1 \%)$ & $86(10.7 \%)$ & $624(17.3 \%)$ & \\
\hline Unclassified & & $9(1.4 \%)$ & $11(1.0 \%)$ & $7(0.7 \%)$ & $8(1.0 \%)$ & $35(1.0 \%)$ & \\
\hline \multicolumn{8}{|l|}{ Frontline caregivers } \\
\hline Doctors & 16.8 & $9(1.4 \%)$ & $63(5.5 \%)$ & $177(17.3 \%)$ & $273(34.1 \%)$ & $522(14.4 \%)$ & $<0.001$ \\
\hline Nurses & 16.8 & $127(19.8 \%)$ & $289(25.2 \%)$ & $250(24.4 \%)$ & $155(19.4 \%)$ & $821(22.7 \%)$ & 0.003 \\
\hline Assistant nurse & 16.8 & $130(20.2 \%)$ & $125(10.9 \%)$ & $56(5.5 \%)$ & $18(2.2 \%)$ & $329(9.1 \%)$ & $<0.001$ \\
\hline Other + & & $23(3.6 \%)$ & $74(6.5 \%)$ & $90(8.8 \%)$ & $81(10.1 \%)$ & $268(7.4 \%)$ & $<0.001$ \\
\hline Relative income $\ddagger$ & 51.1 & $5.9(\mathrm{SD} \pm 1.9)$ & $6.4(\mathrm{SD} \pm 1.8)$ & $6.6(\mathrm{SD} \pm 1.8)$ & $\begin{array}{c}6.8(\mathrm{SD} \pm \\
1.8) \\
\end{array}$ & $\begin{array}{l}6.4(\mathrm{SD} \pm \\
1.8)\end{array}$ & $<0.001$ \\
\hline \multicolumn{8}{|l|}{ Vaccinated against } \\
\hline Flu & 16.0 & $115(17.6 \%)$ & $491(42.3 \%)$ & $778(75.3 \%)$ & $733(91.1 \%)$ & $2117(58.0 \%)$ & $<0.001$ \\
\hline Hepatitis B & 16.1 & $531(81.2 \%)$ & $1020(88.1 \%)$ & $955(92.4 \%)$ & $765(95.1 \%)$ & $3271(89.6 \%)$ & $<0.001$ \\
\hline combined (diphteria/tetanos/polio) & 16.2 & $592(90.7 \%)$ & $1110(96.1 \%)$ & $987(95.7 \%)$ & $758(94.3 \%)$ & $3447(94.6 \%)$ & $<0.001$ \\
\hline whooping cough & 16.3 & $450(68.9 \%)$ & $881(76.3 \%)$ & $833(80.9 \%)$ & $666(82.8 \%)$ & $2830(77.7 \%)$ & $<0.001$ \\
\hline \multicolumn{8}{|l|}{ COVID-19 exposure } \\
\hline Contact with COVID-19 patients & 6.3 & $531(78.7 \%)$ & $931(78.2 \%)$ & $845(80.5 \%)$ & $675(82.6 \%)$ & $3220(79.0 \%)$ & 0.083 \\
\hline Household member with COVID-19 & 7.2 & $296(43.9 \%)$ & $556(46.7 \%)$ & $479(45.6 \%)$ & $381(46.6 \%)$ & $1849(45.8 \%)$ & 0.643 \\
\hline SARS-CoV-2 infection & 6.7 & $124(18.4 \%)$ & $211(17.7 \%)$ & $198(18.9 \%)$ & $142(17.4 \%)$ & $738(18.2 \%)$ & 0.841 \\
\hline $\begin{array}{l}\text { Predisposing conditions } \\
\text { to severe COVID-19 } \mathrm{X}\end{array}$ & 7.3 & $41(6.1 \%)$ & $98(8.2 \%)$ & $107(10.2 \%)$ & $103(12.6 \%)$ & $406(10.1 \%)$ & $<0.001$ \\
\hline $\begin{array}{l}\text { Household member } \\
\text { with condition for severe COVID-19 }\end{array}$ & 8.2 & $145(21.5 \%)$ & $283(23.8 \%)$ & $226(21.5 \%)$ & $167(20.4 \%)$ & $872(21.8 \%)$ & 0.308 \\
\hline
\end{tabular}

† Other: this category includes residents, midwives, physiotherapists, students; $\ddagger$ Relative income was assessed using a semi-quantitative Likert scale ranging from 1 ("I am strongly disadvantaged compared to other staff members") to 10 ("I am strongly advantaged compared to other staff members"; $\chi^{X}$ Any condition among the following: age $\geq 65$ years, cardiovascular disease, complicated diabetes, chronic respiratory disease, obesity, late-stage cirrhosis or active cancer, immunodepression, chronic renal failure $<30 \mathrm{~mL} / \mathrm{min} / 1.73 \mathrm{~m}{ }^{2}$, sickle cell disease, pregnancy at 3rd trimester.

As described in Table 2, the fear of adverse events (severity and frequency) was higher in healthcare workers not willing to get vaccinated. Most (51.8\% to 58.7\%) believed that pharmaceutical companies had a beneficial interest in increasing population vaccination coverage ( $p$-value $<0.001)$. Up to a quarter of them $(13.9 \%$ to $27.7 \%)$ supported that alternative medicine and homeopathy were efficient against COVID-19 ( $p$-value $<0.001)$. Empathy, assessed through five questions, was similar across clusters (Supplementary Figure S1). 
Table 2. Perceptions and beliefs towards vaccination, including COVID-19.

\begin{tabular}{|c|c|c|c|c|c|c|c|}
\hline \multirow{2}{*}{ Characteristics } & Missing & Never & $\begin{array}{c}\text { Hesitating } \\
\text { But Not Willing }\end{array}$ & $\begin{array}{l}\text { Hesitating } \\
\text { But Willing }\end{array}$ & Always & Overall & \multirow[t]{2}{*}{$p$-Value } \\
\hline & $\%$ & $N=675$ & $\mathrm{~N}=1190$ & $\mathrm{~N}=1050$ & $\mathrm{~N}=817$ & $\mathrm{~N}=4349$ & \\
\hline \multicolumn{8}{|l|}{$\begin{array}{l}\text { Perceptions and attitude towards } \\
\text { vaccination and COVID-19 }\end{array}$} \\
\hline $\begin{array}{l}\text { Vaccination can induce severe } \\
\text { adverse events }\end{array}$ & 27.3 & $281(66.1 \%)$ & $579(57.0 \%)$ & $363(37.1 \%)$ & $225(30.3 \%)$ & $\begin{array}{c}1448 \\
(45.8 \%)\end{array}$ & $<0.001$ \\
\hline $\begin{array}{l}\text { Vaccine-related adverse events } \\
\text { are rare }\end{array}$ & 31.8 & $135(20.8 \%)$ & $514(47.2 \%)$ & $575(70.2 \%)$ & 327 (80.1\%) & $\begin{array}{c}1551 \\
(52.3 \%)\end{array}$ & $<0.001$ \\
\hline $\begin{array}{l}\text { It is not necessary to get vaccinated, } \\
\text { as others are vaccinated }\end{array}$ & 16.2 & $52(8.1 \%)$ & $61(5.2 \%)$ & $17(1.6 \%)$ & $7(0.9 \%)$ & $137(3.8 \%)$ & $<0.001$ \\
\hline $\begin{array}{l}\text { Non-mandatory vaccines are } \\
\text { not important }\end{array}$ & 16.5 & $82(12.9 \%)$ & $122(10.6 \%)$ & $57(5.5 \%)$ & $19(2.3 \%)$ & $280(7.7 \%)$ & $<0.001$ \\
\hline $\begin{array}{l}\text { Pharmaceuticals companies are } \\
\text { pushing vaccination in their } \\
\text { beneficial interest }\end{array}$ & 33.2 & $178(58.7 \%)$ & $473(51.8 \%)$ & $360(39.3 \%)$ & $174(22.5 \%)$ & $\begin{array}{c}1185 \\
(40.8 \%)\end{array}$ & $<0.001$ \\
\hline $\begin{array}{l}\text { Pharmaceuticals companies are } \\
\text { important in the public } \\
\text { health perspective }\end{array}$ & 40.4 & $220(48.7 \%)$ & $628(73.5 \%)$ & $617(79.7 \%)$ & $417(81.6 \%)$ & $\begin{array}{c}1882 \\
(72.6 \%)\end{array}$ & $<0.001$ \\
\hline $\begin{array}{l}\text { Vaccine are reducing the } \\
\text { natural immunity }\end{array}$ & 17.8 & $174(30.4 \%)$ & $191(16.6 \%)$ & $71(6.8 \%)$ & $13(1.6 \%)$ & $449(12.6 \%)$ & $<0.001$ \\
\hline $\begin{array}{l}\text { Self-vaccination can } \\
\text { protect others }\end{array}$ & 61.0 & $247(43.6 \%)$ & $493(71.3 \%)$ & $273(79.4 \%)$ & $75(81.5 \%)$ & $\begin{array}{c}1088 \\
(64.2 \%) \\
\end{array}$ & $<0.001$ \\
\hline I am afraid of COVID-19 & 8.3 & $158(23.4 \%)$ & $409(34.4 \%)$ & $383(36.5 \%)$ & $310(37.9 \%)$ & $\begin{array}{c}1325 \\
(33.2 \%)\end{array}$ & $<0.001$ \\
\hline $\begin{array}{l}\text { I am confident in the discovery of } \\
\text { effective therapies for COVID-19 }\end{array}$ & 8.6 & $145(21.5 \%)$ & $479(40.3 \%)$ & $521(49.6 \%)$ & $416(50.9 \%)$ & $\begin{array}{c}1653 \\
(41.6 \%)\end{array}$ & $<0.001$ \\
\hline $\begin{array}{l}\text { Alernative medicine or homeopathy } \\
\text { are efficient against COVID-19 }\end{array}$ & 8.8 & $187(27.7 \%)$ & $165(13.9 \%)$ & $56(5.3 \%)$ & $29(3.5 \%)$ & $474(11.9 \%)$ & $<0.001$ \\
\hline \multicolumn{8}{|l|}{ Mandatory COVID-19 vaccination } \\
\hline $\begin{array}{l}\text { COVID-19 vaccination should be } \\
\text { mandatory for healthcare workers }\end{array}$ & 11.5 & $16(2.4 \%)$ & $185(15.5 \%)$ & $416(39.6 \%)$ & $490(60.0 \%)$ & $\begin{array}{c}1138 \\
(29.6 \%)\end{array}$ & $<0.001$ \\
\hline $\begin{array}{l}\text { COVID-19 vaccination should be } \\
\text { mandatory for general population }\end{array}$ & 11.5 & $10(1.5 \%)$ & $138(11.6 \%)$ & $275(26.2 \%)$ & $333(40.8 \%)$ & $787(20.4 \%)$ & $<0.001$ \\
\hline
\end{tabular}

\subsection{Efficacy, Adverse Events and Length of Immunization Variations on Vaccine Acceptance among Hesitant Healthcare Workers}

Figure 4 displays the raw and relative differences in vaccine acceptance by scenario. Among hesitant healthcare workers, the scenario analysis revealed that any decrease in vaccine efficacy or length of immunization resulted in a decrease in vaccine acceptance. However, the strongest and most negative effect was observed for the situation in which adverse events severity was increasing, even if rare (Supplementary Figure S2).

Indeed, the combination of decreased efficacy, one-year immunization, and severe adverse events (scenario 7 ) lead to a 2.1 drop ( $S D \pm 0.8$ ) in vaccine acceptance from the ideal $(-58.4 \%)$. Moreover, in such conditions, the decrease in efficacy from $100 \%$ to $50 \%$ (scenario 6) only resulted in a 0.3 drop ( $\mathrm{SD} \pm 0.6,-17.9 \%)$ in vaccine acceptance. Finally, when switching from an ideal to a vaccine candidate with severe adverse events (scenario 8 ) the vaccine acceptance dropped by $1.4(\mathrm{SD} \pm 1.0,-38.4 \%)$, whereas moderate but frequent adverse events (scenario 4 ) only lead to a 0.7 drop (SD $\pm 0.8,-18.9 \%$ ).

Consistently, willingness to get vaccinated was inversely correlated with the fear of COVID-19 vaccine composition and its potential adverse effects on the body (Figure 5A-C). Those with the least vaccine acceptance also had the lowest confidence in vaccine efficacy (Figure 5D-F).

\subsection{Mandatory Vaccination}

Less than a third of healthcare workers were willing to accept mandatory vaccination programs, ranging from $2.4 \%$ among those unwilling to get vaccinated to $60 \%$ among those willing. 
A

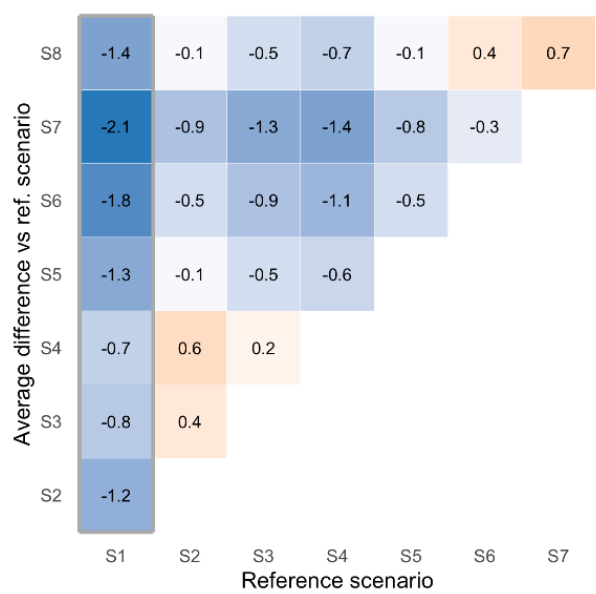



Figure 4. Vaccine willingness across scenarios among hesitating healthcare workers. Absolute (A) and relative (B) differences of the average score for vaccine-willingness (scale from 1 to 4 ) between a reference scenario with an ideal vaccine candidate (abscissa) and subsequent scenarios (ordinate) among hesitating 2240 participants (A). In (B), the relative percentage of variation in mean difference is given.
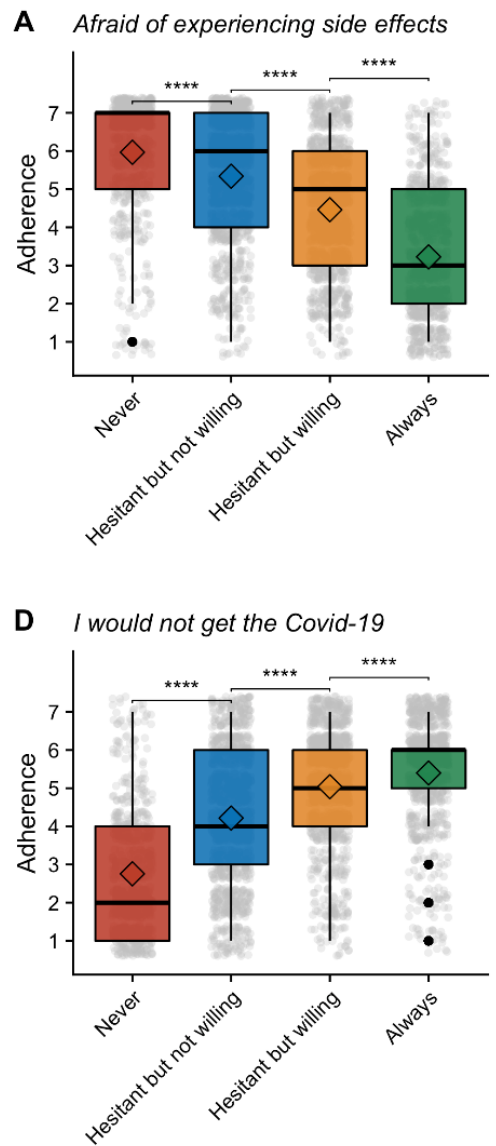

B Afraid of the vaccine contents



E Protection of relatives

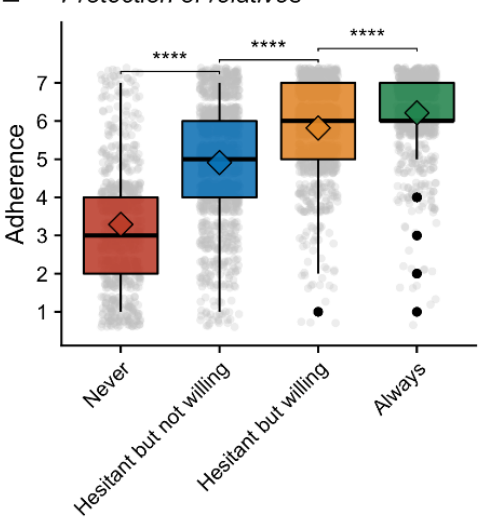

C Afraid of triggering another disease

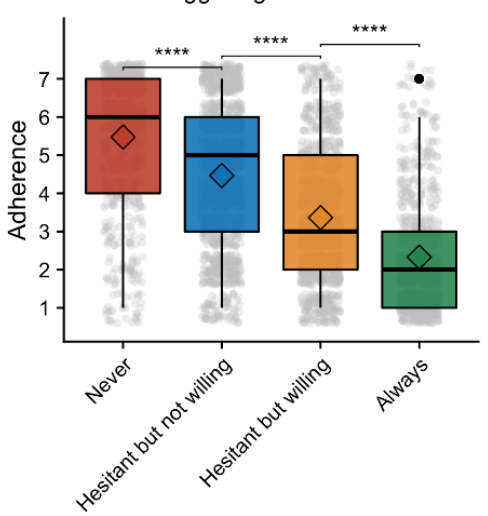

F Less likely to have to stop working

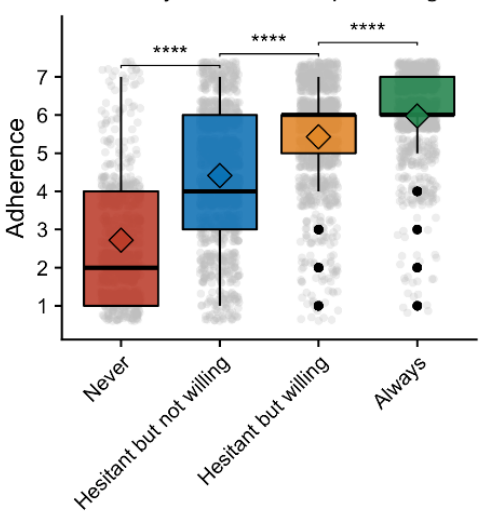

Figure 5. Perception of vaccination against COVID-19 within each cluster. Boxplots of the intensity of perceptions and beliefs about COVID-19, ranging from 1 ("Not at all") to 7 ("Absolutely"). Black dot are representing outliers and greys dots the distribution of answers. For each panel, participants were asked to answer to the question "If you were to be vaccinated against COVID-19 ... ": (A) “ ... I would be afraid of experiencing side effects" (B) “ ... would be afraid of the contents of the vaccine" (C) " ... I would be afraid of triggering another disease" (D) “. . I would not get the virus", (E) “... I would be protecting patients and/or my family", (F) “. . I I would be less likely to have to stop working”. *** for $p$-value <0.001, Wilcoxon-test. 


\section{Discussion}

The willingness to get vaccinated against COVID-19 among healthcare workers increased over time and with the availability of vaccines. After clustering, less than a fifth of health professionals appeared to be firmly reluctant towards vaccination, and most are hesitant. Overall, vaccine willingness grew with age, educational background and was higher among men with underlying conditions. The main determinant of vaccine hesitancy seemed to be the fear of adverse events.

Unsupervised classification methods allowed us to investigate healthcare workers as a heterogeneous population and to identify that a majority were hesitant in their willingness to get vaccinated against COVID-19. Compared to multiple regression models, unsupervised clustering measures average perceptions within subgroups having homogeneous profiles of responses to a set of questions though having different responses to individual questions. Therefore, instead of using a subjective self-reported measurement of vaccine acceptance for identifying hesitant healthcare workers, we are using their global attitude towards vaccination. Such approaches are helpful to use perceptions and attitudes of each cluster towards vaccination in cluster targeted-communication campaigns for increasing vaccine acceptance within hesitant staff members.

As such, safety seems to be a genuine concern for healthcare workers, beyond efficacy and length of immunization. This is highlighted by the recent global alert for the AZD1222 adenovirus vaccine. If a choice were to be given, healthcare workers might favor vaccines with the least side effects, including mRNA vaccines [11,13]. Consistently, a recent cohort study conducted among healthcare workers in England showed that $89 \%$ of the personnel had been vaccinated with the BNT162b2 mRNA vaccine two months after initiating the immunization program. In that study, the characteristics of unvaccinated personnel were similar to those describing our clusters with the lowest vaccine acceptance [14]. Within our cohort, workers having the least willingness to get vaccinated were also the ones having the lowest confidence in institutions and pharmaceutical companies and an incorrect perception of the efficacy of alternative medicines against COVID-19.

The availability of vaccines is likely to be a driver of acceptance in the context of the deadly epidemic persisting. Indeed, the proportion of vaccinated respondents sharply increased after the generalized access to vaccination started in late January. After the 10 March 2021,59\% of respondents to the poll were already vaccinated against COVID-19, versus $46 \%$ in the national surveillance of French healthcare workers [15]. Since mid2020, 15 studies investigated the willingness, and 3 reported the scaling-up of COVID-19 vaccination among healthcare professionals [14,16-38]. Taken together, we can estimate the overall willingness to get vaccinated at $65 \%$ (95CI $56 \%$ to $73 \%$ ) among healthcare workers, with a prediction interval ranging from $18 \%$ to $94 \%$, and varying by region of the globe (Supplementary Figure S3).

Additionally, global acceptance of mandatory immunization programs was low in our study and correlated with higher COVID-19 vaccine acceptance. This suggests that a mandatory scaling-up of vaccination could be counter-productive and may lead to rejection, particularly in populations with little inclination for vaccination. Coverage for hepatitis B was high among professionals not willing to get vaccinated at all, but in France, this vaccine is mandatory for newly hired hospital staff members. On the other hand, these personnel had a $17.6 \%$ coverage for flu. However, from a pragmatic point of view, it seems unrealistic to assess the eligibility for work of caregivers based on their immunization. Communication is therefore essential and should be adapted to healthcare workers' profiles to turn hesitancy into acceptance. As suggested by our study, vaccine acceptance could also increase with its availability and accessibility.

If the number of positive safety reports were to be increased in the coming months, one could expect that anxiety and fear towards adverse event would decrease. Other components such as efficacy, and length of immunization, would become more relevant, especially in light of the emergence of variants of concerns and recombining viruses [39,40]. 
Most (60\%) professionals were hesitant towards vaccination. Despite higher flu vaccine acceptance in the United Kingdom, the recent reporting of $89 \%$ coverage for the first dose of the BNT162b2 mRNA vaccine in England brings hope that hesitant staff will get vaccinated at some point [14]. To that end, training peers using motivational interviewing techniques could also be a promising technique [41,42].

There are many limitations to this study. First, the sample is relatively small and sampling bias with strong opinions about the vaccine. Despite reminders, less than $15 \%$ of the targeted population responded to the survey, and the observed coverage for vaccination can result from a biased selection towards a population likely to accept the vaccine. Additionally, as the self-questionnaire was online and anonymous, we cannot exclude the possibility of duplicated responses. Females represented the majority of our sample, but administrative data describing the workforce of the participating sites showed a similar sex ratio. Nearly two-third received yearly vaccination against influenza, which is higher than usually reported for healthcare workers in France [10]. Most of the respondents were caregivers from public healthcare institutions, while the French National Institute of Statistics and Economies Studies reports that up to $30 \%$ of healthcare workers are administrative personnel, and half of the caregivers are from the private sector. Additionally, three-quarters of the staff members surveyed reported having been vaccinated at the last poll time point. This is higher than the actual national coverage, estimated at $46 \%$ overall [13]. Access to the vaccine was limited to health care workers over 50 years of age during most of the survey period. Therefore, their willingness to be vaccinated may be poorly estimated. Among unvaccinated personnel, we observed a relative decrease in willingness to get vaccinated after the temporary ban of the AZD1222 adenovirus vaccine (10 March 2021) by the European Medical Agency. Interestingly, the features of case scenario \#6 were somehow close to the AZD1222 adenovirus vaccine and were associated in responses to a sharp decrease in vaccine acceptance. However, at the same time, vaccine availability increased, and more than half of the respondents had been vaccinated, inducing a biased measurement for vaccine hesitancy. Second, we did not randomize the scenario assignment, there was no individual follow-up over time, and it was thereby not possible to draw a causal inference. Nevertheless, the sequential ordering of the scenario allowed us to use longitudinal analysis and to identify clusters of respondents based on their trajectories of responses. Finally, vaccine availability will increase over time and possibly lead to an increase in vaccine acceptance. In France, the current trend for the scaling of vaccination is a $0.5 \%$ daily linear increase. However, an asymptote could be reached in the near future. In this perspective, continued monitoring of vaccine coverage and acceptance is crucial.

\section{Conclusions}

Healthcare workers are a heterogeneous population, but most (80\%) could accept the vaccination against COVID-19. Their willingness to get the vaccine increased over time and with access to immunization programs. Among hesitant professionals, the fear of adverse events is the main concern. Targeted information campaigns reassuring about adverse events may increase vaccine coverage in a population with a strong opinion about mandatory immunization programs.

Supplementary Materials: The following are available online at https:/ / www.mdpi.com/article/10 $.3390 /$ vaccines $9060547 / \mathrm{s} 1$, Figure S1: Self-perception of own empathy within each cluster, Figure S2: Effect of efficacy, adverse events, and length of immunization on vaccine acceptance among hesitating healthcare workers, Figure S3: Global willingness to get vaccinated towards COVID-19 among healthcare workers. The study questionnaire.

Author Contributions: Conceptualization, C.J., C.B. and J.G.; Methodology, T.D.; Funding Acquisition, C.J. and T.D.; Project Administration, A.-L.C., C.J. and T.D.; Investigation, the ACV Alpin Study Group; Data Curation, A.M. and T.D.; Formal Analysis, A.M.; Supervision, T.D.; Writing-Original Draft Preparation, A.-L.C., A.M. and T.D.; Writing-Review and Editing, C.J., C.B., J.G. and T.D. All authors have read and agreed to the published version of the manuscript. 
Funding: This study was funded by an academic grant from the Alpine Arc area obtained in 2020. The funding played no role in any of the following: design, data collection, analysis, interpretation, or any aspect pertinent to the study.

Institutional Review Board Statement: Data collected were anonymous, and the confidentiality policy is fulfilling with the European General Data Protection Regulation. In accordance with French regulation (article R. 1121-1 of the public health code), this study does not require the approval of an ethics committee. None of the collected data will be shared with private companies.

Informed Consent Statement: Not applicable.

Data Availability Statement: Anonymized individual-level data, can be shared with academic researchers for 12 months after publication. A codebook corresponding to data reported in the case report form (supplementary materials) is available. Data requests have to be sent at drci.promotion@ ch-annecygenevois.fr. The Study Group will review any request to ensure they are fulfilling with the European General Data Protection Regulation.

Acknowledgments: We thank all the personnel for their participation in the study, as well as hospital directors for allowing data collection and providing access to information about their personnel. We thank the ACV ALPIN Study Group for their participation to the study (alphabetical order): CASH Nanterre and EPS Roger Prévot: Sonbol Asnafi, Fabienne Blanchet, Véronique Bortolotti, Mme Luce Legendre. CH Alpes Léman: M. Clément Caillaux. CH Annecy-Genevois: Mme Caroline Jeannin, Mylène Maillet, Chantal Peigne, Blandine Poulet, and the Clinical Research Unit. CH Andrevetan: Mme Céline Baud, Mme Nathalie Pollez. CH Dufresne Sommeiller: Mme Virginie Delrio-Collin. CH Le Mans: Sophie Blanchi, Mme Angèle Dali-Youcef. CH Métropole Savoie: Mme Céline Cartant, Olivier Rogeaux, Anne-Sophie Wasmer Atoui. CH de Rumilly: Adrien Lotito. CH Vienne: Michèle Cros. CHU Grenoble Alpes: Marion Lemarechal and the Clinical Research Unit. CHU de La Réunion: Léa Bruneau and Marie Lagrange-Xélot. Clinique Générale d'Annecy: Mme Marie-Louise Hervey. CMS Nanterre: Mme Hélène Colombani and Virginie Masse. Etablissement Public de Santé Mentale 74: Jean-Yves Dusseau, Philippe Nicoud, and M. Didier Renaut. Groupe Colisée: Paul-Emile Hay and Mme Anne-Charlotte Rey. Groupement Hospitalier Mutualiste de Grenoble: M. Bernard Bensaïd. Hôpital départemental de Reignier: Mme Agnès Beauhaire. Hôpital Foch: Philippe Lesprit and the Clinical Research Unit. Hôpitaux du Léman: Géraldine Liguori. Hôpitaux du pays du Mont Blanc. HC conseil-Paris: Mme Hélène Chevalier. ISPED—Bordeaux Population Health: Mme Ilaria Montagni; Institut national d'études démographiques: Mme Sabine Mélèze. Stimulus—Paris: Mme Sandrine Levy-Amon. We also would like to thank Julien ARINO (University of Manitoba) for reviewing English.

Conflicts of Interest: Jacques GAILLAT received fees for participation to advisory board or symposium for Pfizer, MSD, and Sanofi Aventis. Cécile JANSSEN received fees for participation to advisory board or symposium for AstraZeneca, Pfizer, Sanofi Pasteur, MSD.

\section{References}

1. Anderson, R.M.; Vegvari, C.; Truscott, J.; Collyer, B.S. Challenges in Creating Herd Immunity to SARS-CoV-2 Infection by Mass Vaccination. Lancet 2020, 396, 1614-1616. [CrossRef]

2. Shah, A.S.V.; Wood, R.; Gribben, C.; Caldwell, D.; Bishop, J.; Weir, A.; Kennedy, S.; Reid, M.; Smith-Palmer, A.; Goldberg, D.; et al. Risk of Hospital Admission with Coronavirus Disease 2019 in Healthcare Workers and Their Households: Nationwide Linkage Cohort Study. BMJ 2020, 371, m3582. [CrossRef] [PubMed]

3. Martin, C.; Montesinos, I.; Dauby, N.; Gilles, C.; Dahma, H.; Van Den Wijngaert, S.; De Wit, S.; Delforge, M.; Clumeck, N.; Vandenberg, O. Dynamics of SARS-CoV-2 RT-PCR Positivity and Seroprevalence among High-Risk Healthcare Workers and Hospital Staff. J. Hosp. Infect. 2020, 106, 102-106. [CrossRef]

4. Haute Autorité de Santé. Stratégie de Vaccination Contre La COVID 19-Anticipation des Scénarios Possibles de Vaccination et Recommandations Préliminaires Sur Les Populations Cibles; Haute Autorité de Santé: Paris, France, 2020.

5. World Health Organization. WHO SAGE Values Framework for the Allocation and Prioritization of COVID-19 Vaccination I Nitag Resource Center; World Health Organization: Geneva, Switzerland, 2020.

6. Giannattasio, A.; Mariano, M.; Romano, R.; Chiatto, F.; Liguoro, I.; Borgia, G.; Guarino, A.; Lo Vecchio, A. Sustained Low Influenza Vaccination in Health Care Workers after H1N1 Pandemic: A Cross Sectional Study in an Italian Health Care Setting for at-Risk Patients. BMC Infect. Dis. 2015, 15, 329. [CrossRef] [PubMed]

7. Blasi, F.; Aliberti, S.; Mantero, M.; Centanni, S. Compliance with Anti-H1N1 Vaccine among Healthcare Workers and General Population. Clin. Microbiol Infect. 2012, 18 (Suppl. 5), 37-41. [CrossRef] 
8. Seasonal Influenza Vaccination and Antiviral Use in EU/EEA Member States. Available online: https:/ / www.ecdc.europa.eu/ en/publications-data/seasonal-influenza-vaccination-antiviral-use-eu-eea-member-states (accessed on 7 December 2020).

9. Sallam, M. COVID-19 Vaccine Hesitancy Worldwide: A Concise Systematic Review of Vaccine Acceptance Rates. Vaccines (Basel) 2021, 9, 160. [CrossRef]

10. Vaux, S.; Fonteneau, L.; Levy-Bruhl, D. Bulletin de Santé Publique Vaccination. Octobre 2019; Santé Publique France: Saint-Maurice, France, 2019. Available online: https:/ / www.santepubliquefrance.fr/determinants-de-sante/vaccination/documents/bulletinnational/bulletin-de-sante-publique-vaccination.-octobre-2019 (accessed on 1 December 2020).

11. European Medicines Agency. COVID-19 Vaccine Safety Update, VAXZEVRIA, AstraZeneca AB; European Medicines Agency: Amsterdam, The Netherlands, 2021.

12. Genolini, C.; Falissard, B. KmL: K-Means for Longitudinal Data. Comput. Stat. 2010, 25, 317-328. [CrossRef]

13. Verger, P.; Peretti-Watel, P. Understanding the Determinants of Acceptance of COVID-19 Vaccines: A Challenge in a Fast-Moving Situation. Lancet Public Health 2021, 6, e195-e196. [CrossRef]

14. Hall, V.J.; Foulkes, S.; Saei, A.; Andrews, N.; Oguti, B.; Charlett, A.; Wellington, E.; Stowe, J.; Gillson, N.; Atti, A.; et al. Effectiveness of BNT162b2 MRNA Vaccine Against Infection and COVID-19 Vaccine Coverage in Healthcare Workers in England, Multicentre Prospective Cohort Study (the SIREN Study); Social Science Research Network: Rochester, NY, USA, 2021.

15. Santé Publique France COVID-19 Vaccination Coverage among Healthcare Worker from France. Available online: https: / / geodes.santepubliquefrance.fr/\#c=indicator\&view=map2 (accessed on 26 March 2020).

16. Amin, D.P.; Palter, J.S. COVID-19 Vaccination Hesitancy among Healthcare Personnel in the Emergency Department Deserves Continued Attention. Am. J. Emerg. Med. 2021. [CrossRef] [PubMed]

17. Szmyd, B.; Bartoszek, A.; Karuga, F.F.; Staniecka, K.; Błaszczyk, M.; Radek, M. Medical Students and SARS-CoV-2 Vaccination: Attitude and Behaviors. Vaccines (Basel) 2021, 9, 128. [CrossRef]

18. Shekhar, R.; Sheikh, A.B.; Upadhyay, S.; Singh, M.; Kottewar, S.; Mir, H.; Barrett, E.; Pal, S. COVID-19 Vaccine Acceptance among Health Care Workers in the United States. Vaccines (Basel) 2021, 9, 119. [CrossRef]

19. Shaw, J.; Stewart, T.; Anderson, K.B.; Hanley, S.; Thomas, S.J.; Salmon, D.A.; Morley, C. Assessment of U.S. Health Care Personnel (HCP) Attitudes towards COVID-19 Vaccination in a Large University Health Care System. Clin. Infect. Dis. 2021. [CrossRef]

20. Verger, P.; Scronias, D.; Dauby, N.; Adedzi, K.A.; Gobert, C.; Bergeat, M.; Gagneur, A.; Dubé, E. Attitudes of Healthcare Workers towards COVID-19 Vaccination: A Survey in France and French-Speaking Parts of Belgium and Canada, 2020. Euro. Surveill. 2021, 26. [CrossRef]

21. Kwok, K.O.; Li, K.-K.; Wei, W.I.; Tang, A.; Wong, S.Y.S.; Lee, S.S. Influenza Vaccine Uptake, COVID-19 Vaccination Intention and Vaccine Hesitancy among Nurses: A Survey. Int. J. Nurs. Stud. 2021, 114, 103854. [CrossRef] [PubMed]

22. Gagneux-Brunon, A.; Detoc, M.; Bruel, S.; Tardy, B.; Rozaire, O.; Frappe, P.; Botelho-Nevers, E. Intention to Get Vaccinations against COVID-19 in French Healthcare Workers during the First Pandemic Wave: A Cross-Sectional Survey. J. Hosp. Infect. 2021, 108, 168-173. [CrossRef]

23. Kabamba Nzaji, M.; Kabamba Ngombe, L.; Ngoie Mwamba, G.; Banza Ndala, D.B.; Mbidi Miema, J.; Luhata Lungoyo, C.; Lora Mwimba, B.; Cikomola Mwana Bene, A.; Mukamba Musenga, E. Acceptability of Vaccination Against COVID-19 Among Healthcare Workers in the Democratic Republic of the Congo. Pragmat. Obs. Res. 2020, 11, 103-109. [CrossRef] [PubMed]

24. Wang, K.; Wong, E.L.Y.; Ho, K.F.; Cheung, A.W.L.; Chan, E.Y.Y.; Yeoh, E.K.; Wong, S.Y.S. Intention of Nurses to Accept Coronavirus Disease 2019 Vaccination and Change of Intention to Accept Seasonal Influenza Vaccination during the Coronavirus Disease 2019 Pandemic: A Cross-Sectional Survey. Vaccine 2020, 38, 7049-7056. [CrossRef] [PubMed]

25. Dror, A.A.; Eisenbach, N.; Taiber, S.; Morozov, N.G.; Mizrachi, M.; Zigron, A.; Srouji, S.; Sela, E. Vaccine Hesitancy: The next Challenge in the Fight against COVID-19. Eur. J. Epidemiol. 2020, 35, 775-779. [CrossRef]

26. Di Gennaro, F.; Murri, R.; Segala, F.V.; Cerruti, L.; Abdulle, A.; Saracino, A.; Bavaro, D.F.; Fantoni, M. Attitudes towards AntiSARS-CoV2 Vaccination among Healthcare Workers: Results from a National Survey in Italy. Viruses 2021, 13, 371. [CrossRef]

27. Kuter, B.J.; Browne, S.; Momplaisir, F.M.; Feemster, K.A.; Shen, A.K.; Green-McKenzie, J.; Faig, W.; Offit, P.A. Perspectives on the Receipt of a COVID-19 Vaccine: A Survey of Employees in Two Large Hospitals in Philadelphia. Vaccine 2021, 39, 1693-1700. [CrossRef]

28. Qattan, A.M.N.; Alshareef, N.; Alsharqi, O.; Al Rahahleh, N.; Chirwa, G.C.; Al-Hanawi, M.K. Acceptability of a COVID-19 Vaccine Among Healthcare Workers in the Kingdom of Saudi Arabia. Front. Med. (Lausanne) 2021, 8. [CrossRef]

29. Robbins, T.; Berry, L.; Wells, F.; Randeva, H.; Laird, S. Healthcare Staff Perceptions towards Influenza and Potential COVID-19 Vaccination in the 2020 Pandemic Context. J. Hosp. Infect. 2021. [CrossRef] [PubMed]

30. Goldman, R.D.; Marneni, S.R.; Seiler, M.; Brown, J.C.; Klein, E.J.; Cotanda, C.P.; Gelernter, R.; Yan, T.D.; Hoeffe, J.; Davis, A.L.; et al. Caregivers' Willingness to Accept Expedited Vaccine Research During the COVID-19 Pandemic: A Cross-Sectional Survey. Clin. Ther. 2020, 42, 2124-2133. [CrossRef] [PubMed]

31. Papagiannis, D.; Malli, F.; Raptis, D.G.; Papathanasiou, I.V.; Fradelos, E.C.; Daniil, Z.; Rachiotis, G.; Gourgoulianis, K.I. Assessment of Knowledge, Attitudes, and Practices towards New Coronavirus (SARS-CoV-2) of Health Care Professionals in Greece before the Outbreak Period. Int. J. Environ. Res. Public Health 2020, 17, 4925. [CrossRef]

32. Schrading, W.A.; Trent, S.A.; Paxton, J.H.; Rodriguez, R.M.; Swanson, M.B.; Mohr, N.M.; Talan, D.A. Project COVERED Emergency Department Network Vaccination Rates and Acceptance of SARS-CoV-2 Vaccination among U.S. Emergency Department Health Care Personnel. Acad. Emerg. Med. 2021. [CrossRef] [PubMed] 
33. Qunaibi, E.; Basheti, I.; Soudy, M.; Sultan, I. Hesitancy of Arab Healthcare Workers towards COVID-19 Vaccination: A Large-Scale Multinational Study. Vaccines 2021, 9, 446. [CrossRef]

34. Nohl, A.; Afflerbach, C.; Lurz, C.; Brune, B.; Ohmann, T.; Weichert, V.; Zeiger, S.; Dudda, M. Acceptance of COVID-19 Vaccination among Front-Line Health Care Workers: A Nationwide Survey of Emergency Medical Services Personnel from Germany. Vaccines (Basel) 2021, 9, 424. [CrossRef]

35. Kasozi, K.I.; Laudisoit, A.; Osuwat, L.O.; Batiha, G.E.-S.; Al Omairi, N.E.; Aigbogun, E.; Ninsiima, H.I.; Usman, I.M.; DeTora, L.M.; MacLeod, E.T.; et al. A Descriptive-Multivariate Analysis of Community Knowledge, Confidence, and Trust in COVID-19 Clinical Trials among Healthcare Workers in Uganda. Vaccines (Basel) 2021, 9, 253. [CrossRef]

36. Kukreti, S.; Lu, M.-Y.; Lin, Y.-H.; Strong, C.; Lin, C.-Y.; Ko, N.-Y.; Chen, P.-L.; Ko, W.-C. Willingness of Taiwan's Healthcare Workers and Outpatients to Vaccinate against COVID-19 during a Period without Community Outbreaks. Vaccines (Basel) 2021, 9, 246. [CrossRef]

37. Szmyd, B.; Karuga, F.F.; Bartoszek, A.; Staniecka, K.; Siwecka, N.; Bartoszek, A.; Błaszczyk, M.; Radek, M. Attitude and Behaviors towards SARS-CoV-2 Vaccination among Healthcare Workers: A Cross-Sectional Study from Poland. Vaccines (Basel) $2021,9,218$. [CrossRef]

38. Papagiannis, D.; Rachiotis, G.; Malli, F.; Papathanasiou, I.V.; Kotsiou, O.; Fradelos, E.C.; Giannakopoulos, K.; Gourgoulianis, K.I. Acceptability of COVID-19 Vaccination among Greek Health Professionals. Vaccines (Basel) 2021, 9, 200. [CrossRef]

39. Edara, V.V.; Norwood, C.; Floyd, K.; Lai, L.; Davis-Gardner, M.E.; Hudson, W.H.; Mantus, G.; Nyhoff, L.E.; Adelman, M.W.; Fineman, R.; et al. Reduced Binding and Neutralization of Infection- and Vaccine-Induced Antibodies to the B.1.351 (South African) SARS-CoV-2 Variant. bioRxiv 2021. [CrossRef]

40. Sarah P., O.; Troy, D.; Julien, A.; Caroline, C.; Jonathan, D.; Michael, L.; Samir, M.; Gary, V.D.; Jianhong, W.; Nicolas, H.O. An Evolving Pandemic: The Origins and Potential Future of COVID-19 Variants of Concern. Curr. Biol. Under review.

41. Borgey, F.; Henry, L.; Lebeltel, J.; Lescure, P.; Le Coutour, X.; Vabret, A.; Verdon, R.; Thibon, P. Effectiveness of an Intervention Campaign on Influenza Vaccination of Professionals in Nursing Homes: A Cluster-Randomized Controlled Trial. Vaccine 2019, 37, 1260-1265. [CrossRef] [PubMed]

42. Lanoix, J.-P.; El Samad, Y.; Schmit, J.-L.; Legrain, A.; Joseph, C.; Smail, A.; Douadi, C.; Adjidé, C.; Merlin-Brochart, J.; Couvreur, V. Effect Of Motivational Team On Influenza Vaccination Coverage Among Health Care Workers. Infect. Dis. (Lond.) 2019, 51, 302-304. [CrossRef] [PubMed] 